\title{
A Review on Adsorbents In Chromatography
}

\author{
Rajeshwar V. Chavan ${ }^{*}$, Manohar D. Kengar ${ }^{2}$, Archna R. Dhole ${ }^{1}$, Vijay R. Salunkhe ${ }^{1}$ \\ ${ }^{1}$ Department of Quality Assurance, Rajarambapu College of Pharmacy, Kasegaon, Maharashtra, India \\ ${ }^{2}$ Department of Pharmaceutics, Rajarambapu College of Pharmacy, Kasegaon, Maharashtra, India \\ Corresponding Author E-mail:-rajchavan6680@gmail.com
}

\begin{abstract}
The Adsorption chromatography only differs from adsorption in how the process operates, not the principle of separation. For adsorption chromatography, the adsorbent is used as the stationary phase. The solute binds to the adsorbent via van der Waal forces and steric interactions. Since the adsorption sites are typical only on the outer surface of the stationary phase, fairly small particles are used as the stationary phase. The technique of chromatography used presently is limited to a few adsorbents and usually to non-aqueous systems, due to the difficulty of elution of the adsorbate. However, aqueous systems could be used if adsorbents were available which permitted adsorption and desorption to be controlled by $\mathrm{pH}$ adjustment. Adsorption is present in many natural physical, biological, and chemical systems and is widely used in industrial applications such as activated charcoal, capturing and using waste heat to provide cold water for air conditioning and other process requirements, synthetic resins, increase storage capacity of carbide-derived carbons for tunable nanoporous carbon and water purification.
\end{abstract}

Keywords : Adsorption Chromatography, Technique Of Chromatography, Column Designs

\section{INTRODUCTION}

An adsorbent is a substance, usually porous in nature and with a high surface area that can adsorb substances onto its surface by intermolecular forces. Only at very low concentrations is the adsorption isotherm linear, at higher concentrations the adsorption isotherm may be Langmuir or Freundlich in nature. Due to the fact that solutes can distribute between the adsorbent surface and a mobile phase, adsorbents are used as a stationary phases in gas-solid and liquid-solid chromatography. Adsorbents are also used for extraction purposes removing traces of organic materials from large volumes of water very efficiently ${ }^{[1]}$. Typical adsorbents are silica gel, alumina, carbon and bonded phases. These are mostly used in the separation of the permanent gases and the low molecular weight hydrocarbon gasses. Adsorbents used in liquid solid chromatography are mostly silica gel and various types of bonded phases. Adsorbents in liquid-solid chromatography have a very wide variety of application areas.

An adsorbent term involves in the chromatography i.e. technique of separation. The history of chromatography begins during the mid-19th century. Chromatography, literally "color writing", was used and named in the first decade of the 20th century, primarily for the separation of plant pigments such as chlorophyll. New types of chromatography developed during the 1930s and 1940s made the technique useful for many types of separation process. Some related techniques were developed during the 19th century but the first true chromatography is 
usually attributed to Russian botanist Mikhail Semyonovich Tsvet, who used columns of calcium carbonate as an adsorbent for separating plant pigments during the first decade of the 20th century during his research of chlorophyll. Chromatography became developed substantially as a result of the work of Archer John Porter Martin and Richard Laurence Millington Synge during the 1940s and 1950s. They established the principles and basic techniques of partition chromatography and their work encouraged the rapid development of several types of chromatography method like paper chromatography, gas chromatography and what would become known as high performance liquid chromatography. Since then, the technology has advanced rapidly. Researchers found that the main principles of Tsvet's chromatography could be applied in many different ways, resulting in the different varieties of chromatography. Simultaneously, advances continually improved the technical performance of chromatography, allowing the separation of increasingly similar molecules. Chromatography is the collective term for a set of laboratory techniques for the separation of mixtures [2].

The technique of chromatography used presently is limited to a few adsorbents and usually to nonaqueous systems, due to the difficulty of elution of the adsorbate. However, aqueous systems could be used if adsorbents were available which permitted adsorption and desorption to be controlled by $\mathrm{pH}$ adjustment. This procedure is possible in some cases with synthetic ion exchange resins which have been used to a limited extent for the separation of mixtures of inorganic ions, organic bases such as thiamine, and some amino-acids. However, organic bases cannot always be recovered quantitatively even by elution with strong acids. Sodium cotton succinate has been used for the quantitative adsorption and recovery of histamine, which could not be eluted quantitatively from ion exchange resins ${ }^{[3]}$.

\section{METHODS AND MATERIAL}

\section{ADSORPTION}

Adsorption is the accumulation of atoms or molecules on the surface of a material. This process creates a film of the adsorbate (the molecules or atoms being accumulated) on the adsorbent's surface. It is different from absorption, in which a substance diffuses into a liquid or solid to form a solution. The term sorption includes both processes, while desorption is the reverse process of "adsorption". In simple terms, adsorption is "the collection of a substance onto the surface of adsorbent solids." It is a removal process where certain particles are bound to an adsorbent particle surface by either chemical or physical attraction. Adsorption is often confused with absorption, where the substance being collected or removed actually penetrates into the other substance [4].

Adsorption is present in many natural physical, biological, and chemical systems and is widely used in industrial applications such as activated charcoal, capturing and using waste heat to provide cold water for air conditioning and other process requirements, synthetic resins, increase storage capacity of carbidederived carbons for tunable nanoporous carbon and water purification

Depending on the nature of attractive forces existing between the adsorbate and adsorbent, adsorption can be classified as:

1. Physical adsorption.

2. Chemical adsorption. 


\section{Physical adsorption (Physisorption):}

In physical adsorption, the forces of attraction between the molecules of the adsorbate and the adsorbent are of the weak van der Waals' type. Since the forces of attraction are weak, the process of physisorption can be easily reversed by heating or decreasing the pressure of the adsorbate (as in the case of gases).

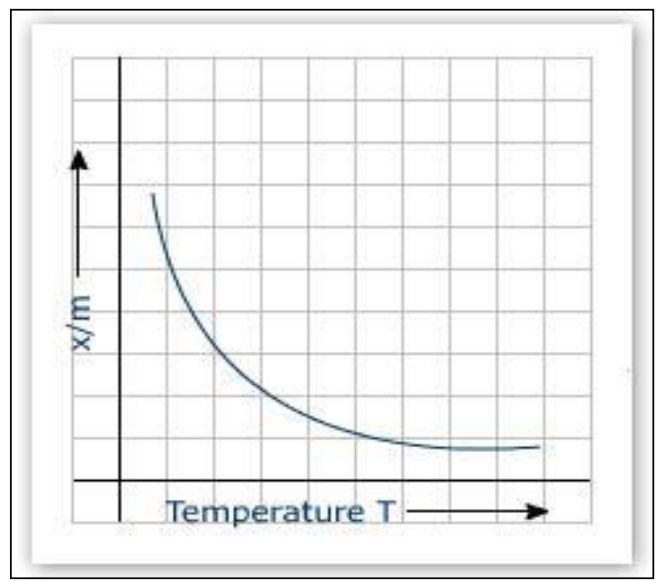

Fig.1: Physical adsorption at given pressure.

\section{Chemical adsorption (Chemisorption):}

In chemisorption, the forces of attraction between the adsorbate and the adsorbent are very strong; the molecules of adsorbate form chemical bonds with the molecules of the adsorbent present in the surface.

Adsorption is generally accompanied by release of energy, that is, most adsorption processes are exothermic in nature. Adsorption is a spontaneous process; therefore its free energy change is negative. Enthalpy of adsorption, which is the enthalpy change for the adsorption of one mole of an adsorbate on an adsorbent surface, is usually in the range of 20 $\mathrm{kJ} / \mathrm{mole}$ to $40 \mathrm{~kJ} / \mathrm{mole}$ while for chemisorptions, the values are of high magnitude, that is, $200 \mathrm{~kJ} /$ mole to $400 \mathrm{~kJ} / \mathrm{mole}$.

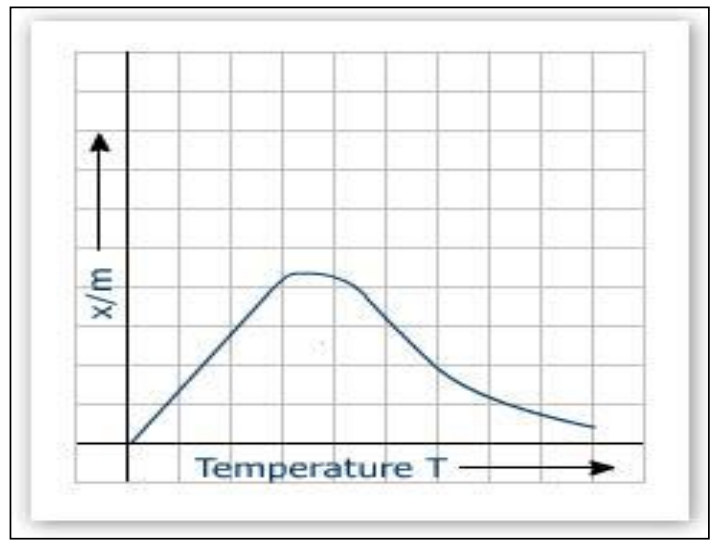

Fig.2 Chemical adsorption at given pressure.

The differences between physisorption and chemisorption are summarized in the below table.

\section{B) ROLE OF ADSORPTION ISOTHERMS:}

Aqueous phase adsorption isotherms and adsorption rates are reviewed. Among numbers of isotherm equations, a combination of adsorption potential and solvophobic concept was applicable to interpreting adsorption equilibrium data obtained for agrochemicals on activated carbon fiber. Intraparticle diffusion becomes the rate-limiting step in liquid phase adsorption on granular activated carbons. Correlation of diffusion coefficients based on surface diffusion mechanisms is introduced. As topics related to adsorption, sediment water partition, biological activated carbon, removal of volatile organics and nutrient removal are briefly reviewed.

\section{Definitions of adsorbents ${ }^{[5,6]}$}

$\checkmark$ An adsorbent is the substrate material onto which a substance is adsorbed.

$\checkmark$ A material having capacity or tendency to adsorb another substance.

$\checkmark$ A substance that is used to adsorb another substance onto its surface. The stationary phase in chromatography. In thin layer chromatography, the paper of the chromatographic plate is the 
adsorbent. In column chromatography, a substance such as silica gel is the adsorbent.

$\checkmark$ A substance that is able to take up a gas, liquid or dissolved substance on a surface in a condensed layer.

A highly porous solid with the ability to concentrate and hold gasses and vapors in contact with the solid. This includes moisture, as well as many other organic and inorganic molecules.

$\checkmark$ A material, usually solid, capable of holding gases, liquids and suspended matter at its surface and in exposed pores.

Adsorbents are used usually in the form of spherical pellets, rods, moldings, or monoliths with hydrodynamic diameters between 0.5 and $10 \mathrm{~mm}$. They must have high abrasion resistance, high thermal stability and small pore diameters, which results in higher exposed surface area and hence high surface capacity for adsorption. The adsorbents must also have a distinct pore structure which enables fast transport of the gaseous vapors.

\section{RESULTS AND DISCUSSION}

\section{Characteristics and general requirements}

Adsorbents are used usually in the form of spherical pellets, rods, moldings, or monoliths with hydrodynamic diameters between 0.5 and $10 \mathrm{~mm}$. They must have high abrasion resistance, high thermal stability and small pore diameters, which results in higher exposed surface area and hence high surface capacity for adsorption. The adsorbents must also have a distinct pore structure which enables fast transport of the gaseous vapors.

Most industrial adsorbents fall into one of three classes:
- Oxygen-containing compounds - Are typically hydrophilic and polar, including materials such as silica gel and zeolites.

- Carbon-based compounds - Are typically hydrophobic and non-polar, including materials such as activated carbon and graphite.

- Polymer-based compounds - Are polar or nonpolar functional groups in a porous polymer matrix.

\section{Important characteristics of good adsorbent ${ }^{[8]}$ :}

- It should have large surface area.

- Available polar site.

- Reproducibility in the degree of action. This measure the adsorbing power and often extent of removal of surface water is the most difficult to control and reproduce.

\section{Requirements of adsorbent ${ }^{[8]}$ :}

- They should be insoluble in solvent.

- They should be chemically inert.

- They should be active but not so active that no movement of component occurs.

- They should be colorless to facilitate observation of zone.

- They should allow suitable flow of mobile phase and reproducible.

Column designs ${ }^{[8]},{ }^{[9]}$ :

\section{a) OBD Column Design:}

With careful tuning of the packing process for each particle type and column geometry the prep Optimum Bed Density design results in predictable, inform density profiles throughout the column. The care should be taken during final packing of column that column packing material not to over compressed or disrupted in any non uniform way. 


\section{b) Load ability by design:}

Successful scale of an isolation and purification process is not only a function of column efficiency but is also related to the loadability of chromatographic material. The physical characteristic of preparative phases, such as surface area and legand density, do not always correlate well with the mass loadabilty of ionisable conpounds. Preparative silica particles have be synthetically designed to deliver maximum loadabilty I an acidic to moderate mobile phase condition.

\section{c) Particle design for purification:}

Preservative packing materials are fully optimized to deliver the maximum efficiency and the highest load ability at the lowest possible back pressures. These attributes allow the purification with the flexibility which is the best combination of particles size and column lamination to easily purify even the most complex of samples.

\section{d) Column performance:}

For a column to remain stable during operation, the bed must be packed sufficiently dense to withstand the compressive fluid forces encountered during use. In the case analytical column dimensions, the necessary packed bed density can generally be achieved by using slurry packing method. As the length and diameter of the column increases, it becomes increasingly difficult to reach the bed density required for stable, long term performance when used in small particles.

\section{e) Column stability and reliability:}

The demand for rapid high purity compound isolation places strong emphasis on the integrity and stability of the prep column. Complex, sparingly soluble starting materials are often dissolving with strong solvents. The combination of poor solubility and pressure shocks associated with large injection volumes of pure organic solvents are primary contributors to early column failure and chromatography bed collapse.

Study of various chromatographic adsorbents [10], [11]: to keep the city clean by informing about the garbage levels of the bins by providing graphical image of the bins via IOT Php web development platform.

1. Silica Gel Column Chromatography

2. Activated Alumina Balls

3. Carbon adsorbents

4. Activated carbon adsorbents

5. Cation exchange columns

6. Aluminium oxide adsorbents

7. HPLC Columns

8. Advanced purification glass columns

9. Columns for polymer characterization

10. High Resolution ion exchange glass column

\section{FUTURE ASPECTS OF ADSORBENTS}

[12], [13], [14], [15], [16]

\section{Hydrogen storage using carbon adsorbents: past, present and future:}

Hydrogen storage technologies must be significantly advanced if a hydrogen based energy system, particularly in the transportation sector, is to be established. Hydrogen can be made available onboard vehicles in containers of compressed or liquefied $\mathrm{H}_{2}$, in metal hydrides, via chemical storage or by gas-on-solid adsorption. Although each method possesses desirable characteristics, no approach satisfies all of the efficiency, size, weight, cost and safety requirements for transportation or utility use. Gas-on-solid adsorption is an inherently safe and potentially high energy density hydrogen storage method that could be extremely energy efficient. The 
hydrogen storage properties of high surface area activated carbons have been extensively studied.

\section{Separation of citric acid from fermentation broth} with a neutral polymeric adsorbent:

Citric acid is separated from a fermentation broth by using an adsorbent comprising a neutral, noniogenic, macroreticular, water-insoluble, crosslinked styrenepoly(vinyl)benzene and a desorbent comprising water and, optionally, acetone with the water. The $\mathrm{pH}$ of the feed is adjusted and maintained below the first ionization constant (pKa) of citric acid to maintain selectivity.

\section{Preparation of Modified Clay Adsorbents for the Removal of Humic Acid:}

By replacing the natural interlayer cations of montmorillonites with polymeric $\mathrm{Al} / \mathrm{Fe}$ species, the properties of clay surfaces can be modified, and this allows them to interact with both organic and inorganic pollutants dissolved in water. The order of the affinity of various clays to humic acid is: polymeric $\mathrm{Fe} / \mathrm{Al}$-modified $>$ polymeric $\mathrm{Al}$-modified > polymeric Fe modified $>$ unmodified (starting) clay, and this demonstrates that polymeric $\mathrm{Al} / \mathrm{Fe}$-modified montmorillonites are potential efficient adsorbent for treating color-causing natural organic matter.

\section{Uses of a-Fe2O3 and fly ash as solid adsorbents:}

Solid adsorbents have shown great promise for control of particulate and non-particulate matter and as gas sensing devices in recent times. In the present study, adsorption of environmental toxic pollutant such as lead ions on solid adsorbents viz. a-Fe2O3 and fly ash, are used. Considerable adsorption was observed on fly ash when compared to a-Fe2O3 surface.
5. Process chromatography: current constraints and future options for the adsorptive recovery of bioproducts:

A contemporary review of adsorption chromatography must embrace aspects of fixed bed, batch suspension and fluidized-bed contacting of complex feedstocks with adsorbents chemically derivatised with ligands with binding specificities for target bioproducts. Advances in the design of adsorbents, ligands and contactors have facilitated opportunities for integrated processing of unclarified feedstocks to benefit purity and yield of macromolecular products.

\section{v. CONCLUSION}

The technique of chromatography used presently is limited to a few adsorbents and usually to nonaqueous systems, due to the difficulty of elution of the adsorbate. Chromatographic techniques were used to separate substances based on their color as was the case with herbal pigments. With time its application area was extended considerably. Nowadays, chromatography is accepted as an extremely sensitive and effective separation method. Column chromatography is one of the useful separation, and determination methods. Column chromatography is a protein purification method realized especially based on one of the characteristic features of proteins. Besides, these methods are used to control purity of a protein.

\section{ACKNOWLEDGEMENT}

Authors are highly Acknowledge the help of teaching staff of Rajarambapu College of Pharmacy, Kasegaon. For providing necessary information required for review work. Also we are highly Acknowledge the help and guidance of Mss. A. R. Dhole and Dr. V. R. Salunkhe. 


\section{REFERENCES}

[1]. Kevin Scott, Online chromatography, Available on Online http://www.chromatographyonline.org/topics/adsorbents.html.

[2]. Available on Online http://scholar.google.co.in/scholar?hl=en\&q.

[3]. J. K. Carlton, and W. C. Bradbury, Use of Mixed Adsorbents in Chromatographic Separation of Organic Compounds, Anal. Chem, 1955:27 (1): 67-70.

[4]. Haleem J. Issaq, Modifications of Adsorbent, Sample and Solvent in Thin Layer Chromatography, Journal of liquid chromatography 3:10:1423-1435.

[5]. Alderhout, J. J. H., Koch, G. K., and Aten, Jr., A. H. W., Rec. trav. chim., 1957:76:712.

[6]. Van Dam, M. J. D., de Kleuver, G. J., and de Heus, J. G., J. Chromatography., 1960:4:26.

[7]. Mark Baynham, Chromatography Columns and supplies Catalog, Waters Corporation Milford MA, U. S. 2008:144-196.

[8]. R. L. Bieleski, N. A. Turner, Separation and estimation of amino acids in crude plant extracts by thin-layer electrophoresis and chromatography, Analytical Biochemistry,1966:17:( 2):278-293

[9]. Irena M.Choma Edyt, M.Grzelak,Bioautography detection in thinlayer chromatography, Journal of Chromatography A, 2011:19(13) : 2684-269.

[10]. Donald C. Malins, Helmut K. Mangold, Analysis of complex lipid mixtures by thin-layer chromatography and complementary methods, American Oil Chemists' Society, 1960; 37(11):576-578.

[11]. Jia-Qian Jiang, Colin Cooper. Environmental Engineering Science, 2003; 20 :( 6): 581-586. Available on online http://www.liebertonline.com/doi/abs.
[12]. Journal Applied Physics A: Materials Science \& Processing A.C. Dillon and M.J. Heben Publisher Springer Berlin/Heidelberg2001:72:(2):133-142. Available on online http://www.springerlink.com/content.

[13]. Yao WeiRong, Yao HuiYuan,Adsorbent Characteristics of Porous Starch, Biosynthesis nutrition biomedical, 2002:54(6):260-263.

[14]. J. N. Egila , B. E. N. Dauda , Y. A. Iyaka,T. Jimoh, Agricultural waste as a low cost adsorbent for heavy metal removal from wastewater, International Journal of the Physical Sciences, 2011: 6(8): 2152-2157.

[15]. S. G. Wang, R. Z. Wang, X. R .Li ,Research and development of consolidated adsorbent for adsorption systems, Renewable Energy,2005: 30(9):1425-1441.

[16]. Amuda O.S., Ibrahim A.O,Industrial wastewater treatment using natural material as adsorbent, African Journal of Biotechnology 2006: 5 (16):1483-1487.

\section{Cite this article as :}

Rajeshwar V. Chavan, Manohar D. Kengar, Archna R. Dhole, Vijay R. Salunkhe, "A Review on Adsorbents In Chromatography", International Journal of Scientific Research in Science and Technology (IJSRST), Online ISSN : 2395-602X, Print ISSN : 2395-6011, Volume 6 Issue 3, pp. 36-42, May-June 2019. Available at doi :

https://doi.org/10.32628/IJSRST19636

Journal URL : http://ijsrst.com/IJSRST19636 